\title{
The Analysis of Heat Exchangers Geometry in Thermoelectric Generators for Waste Heat Utilization
}

\author{
Marcin Borcuch ${ }^{1, a}$, Stanisław Gumuła ${ }^{1}$, Michał Musiał ${ }^{1}$ and Krzysztof Wojciechowski ${ }^{2}$ \\ ${ }^{1}$ Department of Thermal Engineering and Fluid Flow, Faculty of Energy and Fuels \\ ${ }^{2}$ Thermoelectric Technology Laboratory, Faculty of Materials Science and Ceramics, AGH University of Science and Technology, \\ Al. A. Mickiewicza 30, 30-059 Cracow, Poland
}

\begin{abstract}
The paper presents results of the analysis and comparison of the hot-side heat exchangers (HHXs) dedicated for the thermoelectric generators (TEGs). Efficient operation of TEG depends on, i.a. proper design of the HHX. Six geometries of the heat exchangers' cross-section have been investigated and analysed in view of heat transfer effectiveness $\left(\eta_{\mathrm{TH}}\right)$ and pressure drop $(\Delta \mathrm{P})$. As an assumption, useful heat exchange surface has been set up as $2400 \mathrm{~cm}^{2}$, maintaining heat exchanger (HX) length as $30 \mathrm{~cm}$, which is enough for the placement of the 32 thermoelectric modules able to generate at least $160 \mathrm{~W}$ of the electrical power. The source of waste heat are flue gases, in the analysis approximate as an air. Cold-side heat exchanger (CHX) has been simplified and calculated as a water flow around the casing of the HHX to achieve comparable results. As a base, circular profile has been presented. Numerical calculations provide results suggesting which shape is most suitable for specified application. Results could be the first guidelines for selecting and designing the HX for the TEG. Further investigation will focus on optimization of the chosen $\mathrm{HX}$ in view of increasing $\eta_{\mathrm{TH}}$ and minimizing $\Delta \mathrm{P}$.
\end{abstract}

\section{Introduction}

Increasing awareness of waste energy losses, especially waste heat, causes constant development in the recovery solutions. Among a wide range of waste heat harvesting solutions, thermoelectric generation seems to be competitive and with current progress in thermoelectric materials, TEG in close future could be a significant rival not only in waste heat recovery area but also in Renewables, between photovoltaic and wind energy. TEG is a device used for heat conversion into electrical energy. As a result of Seebeck phenomenon, due to temperature difference between hot and cold sides of thermoelectric module, heat flux is converted into electrical energy with the defined efficiency. The efficiency of a TEG as a whole device depends on both, the efficiency of the thermoelectric modules and the effectiveness of the HXs on the cold and on the hot sides. Big effort is put in development of TEGs to achieve more efficient constructions for different applications [1-6]. Location of the TEG varies from its usage for supplying residential boilers in electrical energy [1], projects of wood stoves able to generate heat, electricity and hot water [2], through cement rotary kilns with energy recovery unit [3], to automotive applications [4-6]. Especially the possibility of replacing the alternator in the cars seems to be one of the best economically justified locations of the TEG.

Despite big benefits from clean heat-into-electricity conversion in TEGs, there still is a big need to optimize

${ }^{a}$ Corresponding author: borcuch@agh.edu.pl the constructions of $\mathrm{HXs}$ and thermoelectric modules. HX in TEG can be treated as two separate elements, each for the hot and the cold side of thermoelectric module (Figure 1).

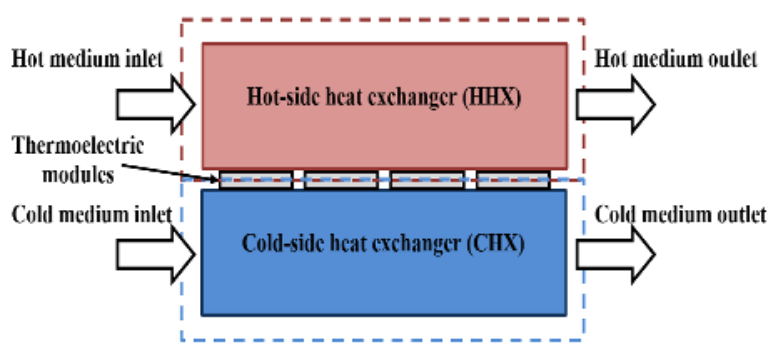

Figure 1. Scheme of the TEG.

In that approach, HHX is a crucial part, which is responsible for effective heat removal from the source. Most common applications of the TEG focus on waste heat harvesting from exhaust and flue gases, so the HHX should effectively remove heat from the gas and transport it to the module connected with the HX surface. High $\eta_{\mathrm{TH}}$ and minimal $\Delta \mathrm{P}$ are the two most important parameters in choosing and designing of the HHX. Rectangular [7], square [8], hexagonal [9] as well as octagonal [10] shapes of HHX have been analysed so far by many research teams. Moreover, cost of manufacturing such HXs has to be taken into account in the designing process. HXs are often equipped with elements for increasing the heat transfer, like fins and insertions [11,12], however 
comparison of pure geometries is necessary to relate exchangers to each other.

The paper presents the comparison and analysis of six HHX' profiles in view of heat utilization and pressure losses. Numerical analysis has been carried out with defined assumptions and obtained results have been interpreted. Square, rectangular, pentagonal, hexagonal, octagonal and as a reference circular shapes of HXs' cross sections were analysed and compared in view of $\eta_{\mathrm{TH}}$ and $\Delta \mathrm{P}$ for varied mass flow rates.

\section{Methodology}

Commonly considered TEG's application is generation of electrical energy from waste heat contained in flue gases from domestic gas boiler [8]. Creation of selfpowered heating unit, independent of the grid is a promising opportunity, especially for regions with unstable grid and frequently occurring blackouts. Decreasing energy demand of pumps and other boiler's equipment leads to lower of electrical energy consumption. For typical purposes, demanded electrical power of a gas boiler is in a range from $80 \mathrm{~W}$ to $160 \mathrm{~W}$. Thus, TEG dedicated for this application should generate such power. Furthermore, usage of waste heat from flue gases will improve the overall efficiency of the system. Proper choose and design of the HHX is crucial for the effective heat utilization from flue gases. The numerical analysis of selected geometries of HHXs have been performed in ANSYS CFX. To obtain comparable results, pure aluminium profiles of $2 \mathrm{~mm}$ thickness were set as HXs. Flue gases were simulated by hot air, whole lateral surface has been cooled by water flow around the casing to avoid dissimilarities caused by the design and mismatching of the CHX.

\subsection{Assumptions}

TEG consists of the HHX, the CHX and the thermoelectric modules. To generate $160 \mathrm{~W}, 32$ modules are required in the TEG. Modules are placed between HHX and CHX. Assuming dimensions of the module as a $5 \mathrm{~cm} \mathrm{x} 5 \mathrm{~cm}$ square, $800 \mathrm{~cm}^{2}$ of the exchanger will be covered by the modules. Including spacing and insulations, the overall heat exchange area, which is equal to the lateral surface of the HHX is set as $2400 \mathrm{~cm}^{2}$ (Table 1). Taking into account the length of the device, which should not be too high because of the possibility to mount it $(30 \mathrm{~cm})$, the cross-section surface areas can be calculated for all shapes.

Table 1. Analysed cross-sections of heat exchangers.

\begin{tabular}{|c|c|c|c|}
\hline Profile & $\begin{array}{c}\text { Cross-section shape } \\
\text { and the lengths of } \\
\text { the sides/diameter }\end{array}$ & $\begin{array}{c}\text { Inlet or } \\
\text { outlet } \\
\text { surface } \\
\text { area }^{1}\end{array}$ & $\begin{array}{c}\text { Heat } \\
\text { transfer } \\
\text { surface } \\
\text { area }^{2}\end{array}$ \\
\hline Square & $\begin{array}{l}20 \\
(\mathrm{~cm})\end{array}$ & $400 \mathrm{~cm}^{2}$ & $2400 \mathrm{~cm}^{2}$ \\
\hline
\end{tabular}

\begin{tabular}{|c|c|c|c|}
\hline Rectangle & $\begin{array}{r}\square 0 \\
\square\end{array}$ & $200 \mathrm{~cm}^{2}$ & $2400 \mathrm{~cm}^{2}$ \\
\hline Pentagon & & $440.4 \mathrm{~cm}^{2}$ & $2400 \mathrm{~cm}^{2}$ \\
\hline Hexagon & & $463 \mathrm{~cm}^{2}$ & $2403 \mathrm{~cm}^{2}$ \\
\hline Octagon & & $482.8 \mathrm{~cm}^{2}$ & $2400 \mathrm{~cm}^{2}$ \\
\hline Circle & & $510.5 \mathrm{~cm}^{2}$ & $\begin{array}{c}2402.1 \\
\mathrm{~cm}^{2}\end{array}$ \\
\hline
\end{tabular}

${ }^{1}$ Cross-section surface area, ${ }^{2}$ Lateral surface of the exchanger.

\subsection{Mesh generation}

All meshes were created in the same way. Water surrounding the casing and air filled it were inflated near the boundary to obtain better solution. Average orthogonal quality of the mesh was in the range from 0.84 to 0.89 (Table 2), which is a very good result. Generated mesh for each case consists of three main parts (Figure 2):

- aluminium HX,

- air inside the HX,

- cooling water around the HX.

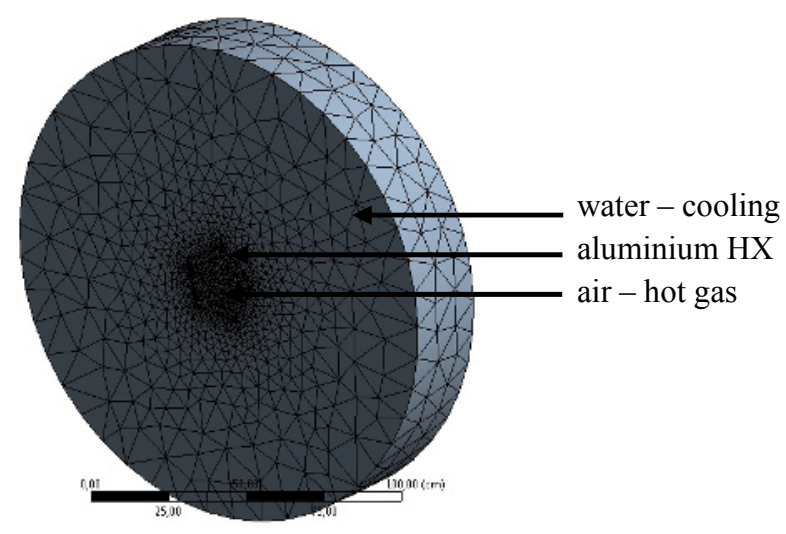

Figure 2. Main parts of generated mesh.

Table 2. Mesh quality.

\begin{tabular}{|c|c|c|c|}
\hline Profile & Nodes & Elements & $\begin{array}{c}\text { Average } \\
\text { orthogonal } \\
\text { quality }\end{array}$ \\
\hline Square & 50536 & 151943 & 0.85 \\
\hline Pentagon & 54138 & 162428 & 0.87 \\
\hline Hexagon & 66545 & 241658 & 0.89 \\
\hline Rectangle & 44932 & 124483 & 0.84 \\
\hline Circle & 62664 & 211330 & 0.89 \\
\hline Octagon & 56081 & 190280 & 0.88 \\
\hline
\end{tabular}




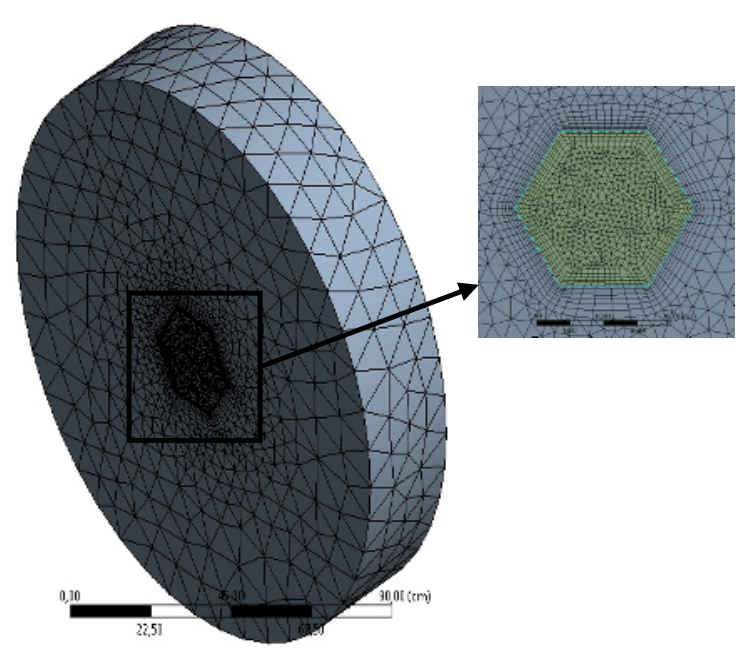

Figure 3. Generated mesh for analysis of hexagonal shape HX.

Mesh close to HX, both, on the air and the water sides has been refined to obtain more accurate results in this volume (Figure 3). Departing from the aluminum profile, temperature gradient is lower, so the density of the mesh also decreases.

\subsection{Solver settings and calculated parameters}

All analysed cases have been set with the same settings and boundary conditions:

- air ideal gas,

- $\quad$ inlet air temperature $=200^{\circ} \mathrm{C}$,

- inlet water speed $=1 \mathrm{~m} / \mathrm{s}$,

- $\quad$ inlet water temperature $=25^{\circ} \mathrm{C}$.

Spatially averaged governing equations for mass, momentum and energy were solved on control volumes to obtain temperatures and $\Delta \mathrm{P}$ for fluid domain. Moreover, energy equation was solved for casing due to heat conduction in solid domain. Turbulence modelling was performed with Shear Stress Transport RANS model. The residual target was set as $10^{-5}$ to obtain accurate results. The same simulation was performed for each profile for varied mass flow rate, due to investigate their performance within typical and high flue gases mass flow rate values. It is related to domestic gas boilers and industrial devices to expand analysed scope. In the range from $0.01 \mathrm{~kg} / \mathrm{s}$ to $0.1 \mathrm{~kg} / \mathrm{s}$ steady-state simulation has been calculated with the interval of 0.01 $\mathrm{kg} / \mathrm{s}$, for the range from $0.1 \mathrm{~kg} / \mathrm{s}$ to $1 \mathrm{~kg} / \mathrm{s}$, interval was equal to $0.1 \mathrm{~kg} / \mathrm{s}$.

Calculated parameters in all simulations were as following:

- $\quad$ area average $\Delta \mathrm{P}$ between the inlet and the outlet of air flow,

- air outlet temperature (decrease due to water cooling),

- heat flux through lateral surface of the HX.

\section{Results}

\subsection{Heat transfer effectiveness}

The $\eta_{\mathrm{TH}}$ is estimated by two approaches:

- by defining the hot gas outlet temperature (Figure 4), where the difference between inlet and outlet temperatures is caused by the energy transfer from the air to the cooling water.

- By calculating the average heat flux through the heat exchange surface (Figure 5, Figure 6). Obtained values are area averaged.



Figure 4. Hot gas outlet temperatures.

The dependency between mass flow rate of hot gas and average temperature at the outlet surface is similar for all profiles. The most effective heat transfer occurs in the rectangle $\mathrm{HX}$. With increasing mass flow rate, the temperature difference between the inlet and the outlet of HX becomes smaller, the hot fluid is not able to cool off on $30 \mathrm{~cm}$ length of the HX. Although, the average heat flux increases with the increment of mass flow rate (Figure 5, Figure 6).

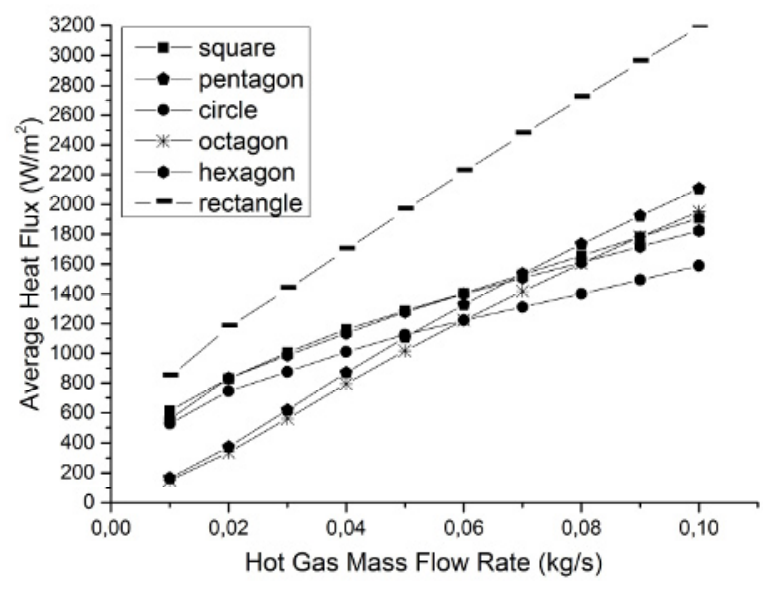

Figure 5. Area averaged heat fluxes.

The dependency between average heat flux and mass flow rate is similar for flows in all ranges of mass flow rates. Water temperature is stable, so the temperature difference is increasing. The best $\eta_{\mathrm{TH}}$ is obtained 
for rectangular HX. Its domination is clearly seen is all range of flows. Omitting rectangular profile, for small flow rates, between 0.01 to $0.05 \mathrm{~kg} / \mathrm{s}$, square and hexagonal HX present the highest values of energy transferred from the flue gases to the coolant (Figure 5). For higher flow rates, pentagonal and octagonal HX have better heat transfer characteristics. Circular HX, calculated as a reference case, presents the worst results in view of heat transfer possibilities.



Figure 6. Area averaged heat fluxes.

Comparing outlet temperatures and average heat fluxes, the order of profiles is the same, starting from the most efficient HX: rectangular, pentagonal, octagonal, square, hexagonal and circular.

\subsection{Pressure drop}

Application of the TEG in the installation with the gas boiler will cause the occurence of the additional pressure losses. HX with the lenght equal to $30 \mathrm{~cm}$ can be treated as a local resistance with specfied $\Delta \mathrm{P}$, dependent on gas flow rate. Calculated charasteristics (Figure 7, Figure 8) presents the connection between $\Delta \mathrm{P}$ and hot gas mass flow rate for all profiles.



Figure 7. Pressure drop in the HX.
Pressure losses increase with the increment of the mass of the gas flowing through the HX. Big difference is visible between $\Delta \mathrm{P}$ in rectangular $\mathrm{HX}$ and the others. Much larger losses are caused in the installation with the application of such element. This dependency is the same for all flow rates. The smallest $\Delta \mathrm{P}$ is caused by the circular $\mathrm{HX}$, which simulaniously validates presented data, because circular pipes have the best flow characteristics. For square, pentagonal, hexagonal and octagonal $\mathrm{HX}$, pressure losses are relatively small.

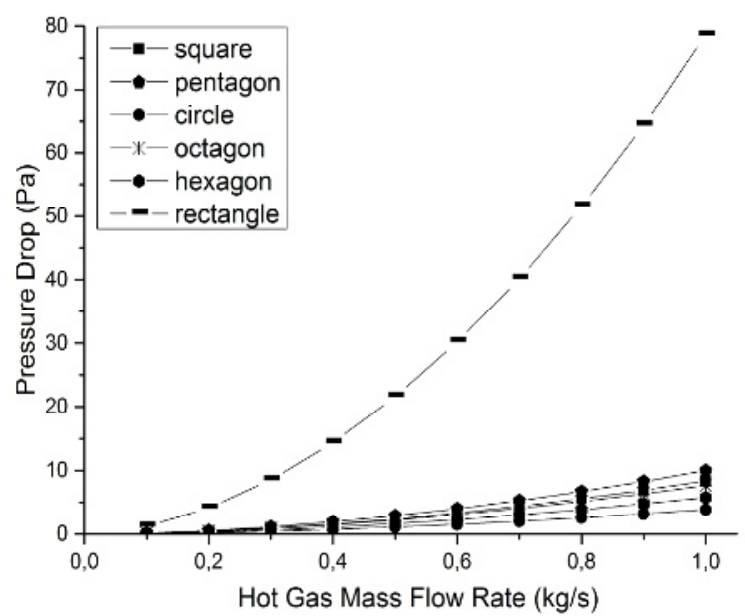

Figure 8. Pressure drop in the HX.

The highest heat transfer effectiveness but also the highest pressure losses characterise the rectangular HX. To compare all shapes, taking into account both factors, an additional analysis is necessary.

The heat transfer surface area is estimated as $2400 \mathrm{~cm}^{2}$. The area, covered by 32 thermoelectric modules is equal to $800 \mathrm{~cm}^{2}$. The heat flux, flowing through the thermoelectric modules will be converted into electrical energy with specified efficiency, according to the type and model of the module. The only input is the additional power, needed to overcome the power losses caused by $\Delta \mathrm{P}$. The net power, generated in each HX can be calculated as:

$$
\begin{gathered}
P_{T E G}=P_{H F} \cdot \eta_{T E}-P_{\Delta P} \\
P_{\Delta P}=\Delta P \cdot \dot{V}
\end{gathered}
$$

$\mathrm{P}_{\mathrm{TEG}}$ net power generated in the TEG [W]

$\mathrm{P}_{\mathrm{HF}}$ thermal power transferred from the hot gas to the coolant through the thermoelectric modules [W]

$\eta_{\mathrm{TE}}$ efficiency of thermoelectric modules [-]

$\mathrm{P}_{\Delta \mathrm{P}}$ power losses due to pressure drop [W]

$\dot{V} \quad$ volumetric flow rate $\left[\mathrm{m}^{3} / \mathrm{s}\right]$

Usage of commercially available modules with the efficiency about $5 \%$ for analysed HXs leads to obtaining not satisfactory results in the net power (Figure 9). High flow rates are necessary to generate more than $30 \mathrm{~W}$ of electrical power. In the case with rectangular $\mathrm{HX}$, in some point, losses become greater than generated energy and application of that kind of TEG results only in net losses. 


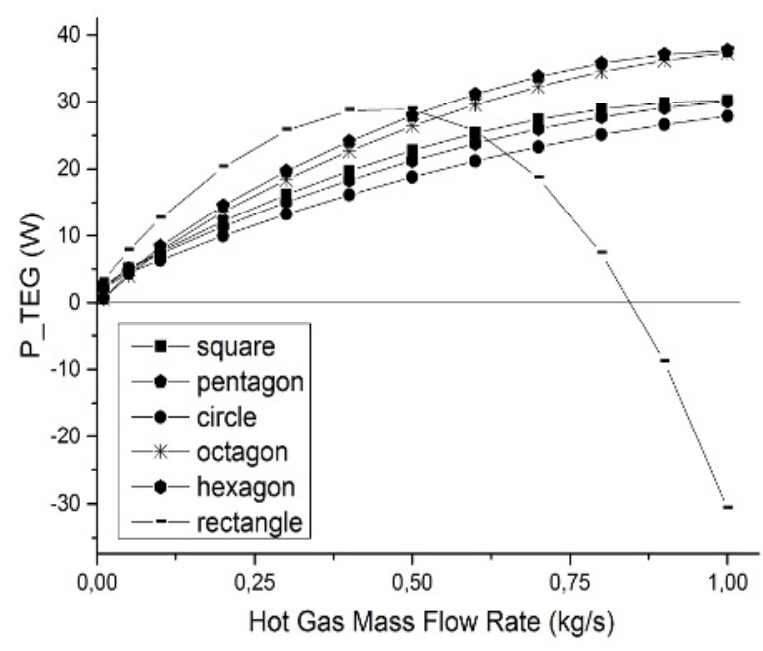

Figure 9. Net power generated in the TEG, $\eta_{\mathrm{TE}}=5 \%$, surface covered by thermoelectric modules in $33 \%$.

Usage of the modules with newly developed materials, with the average efficiency about $10 \%$ benefits in the increase of net generated power (Figure 10). Surface equal to $800 \mathrm{~cm}^{2}$, covered by the thermoelectric modules allows to supply equipment with small energy demand.

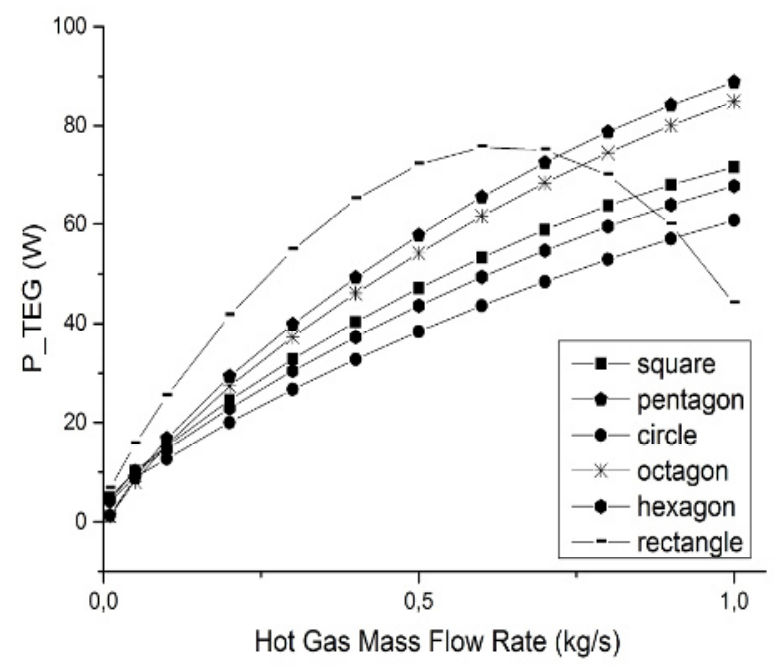

Figure 10. Net power generated in the TEG, $\eta_{\mathrm{TE}}=10 \%$, surface covered by thermoelectric modules in $33 \%$.

Covering the entire surface with thermoelectric modules significantly increases net generated power (Figure 11, Figure 12).

Usage of the modules with the efficiency about $10 \%$ allows to generate more than $300 \mathrm{~W}$ of electrical energy, which is sufficient to supply gas boiler as well as another electrical devices.

Besides the rectangular $\mathrm{HX}$, in which despite the highest heat transfer effectiveness, the power losses have to be taken into account, the pentagonal and octagonal profiles present the best net generated power characteristics.



Figure 11. Net power generated in the TEG, $\eta_{\mathrm{TE}}=5 \%$,surface covered by thermoelectric modules in $100 \%$.

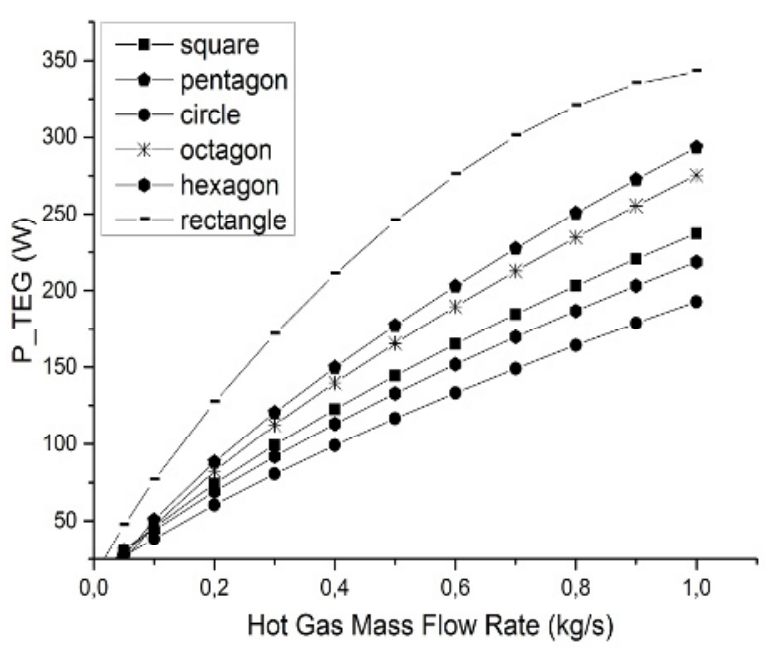

Figure 12. Net power generated in the TEG, $\eta_{\mathrm{TE}}=10 \%$, surface covered by thermoelectric modules in $100 \%$.

Starting of the outlet temperature, through the pressure drop, to area averaged heat transfer, the order of profiles remains the same. Rectangular HX presents the highest heat transfer effectiveness and the biggest pressure losses. It is followed by pentagonal, octagonal, square, hexagonal and circular profiles. The order of profiles obtained in the analysis is not consistent with the order of profiles determined by increasing or decreasing the number of sides. Presented data in next step will be verified experimentally. Moreover, the CHX will be included into analysis.

\section{Conclusions}

Numerical analysis of six HXs profiles has been carried out. The net generated power, taking into account losses due to pressure drop is presented for varied mass flow rates. The highest $\eta_{\mathrm{TH}}$ is obtained for the rectangular HX. Although, taking into account pressure losses, this profile is applicable only for high mass flow rates of hot medium. The circular HX, which has been calculated as a reference, presents the worst characteristics. Besides 
the others profiles, pentagonal HX seems to be optimal in view of $\eta_{\mathrm{TH}}$ and $\Delta \mathrm{P}$.

Analysed profiles were clear, without any insertions and fins. For increasing the $\eta_{\mathrm{TH}}$, some modifications are required. Usage of fins will increase $\Delta \mathrm{P}$ and simultaneously improve $\eta_{\mathrm{TH}}$, so the optimal configuration should be specified and verified. Also other modifications will be implemented, maintaining $\Delta \mathrm{P}$ as low as possible.

\section{Acknowledgments}

This study has been supported by the statutory funds of AGH UST, No. 11.11.160.438 and grant No. 15.11.210.325.

\section{References}

1. K.Qiu, A.C.S Hayden, J Electron Mater, 40, 5, 606610 (2011)

2. A. M. Goudarzi, P. Mazandarani, R. Panahi, H. Behsaz, A. Rezania, L. A. Rosendahl, J Electron Mater, 42, 7, 2127-2133 (2013)

3. Q. Luo, P. Li, L. Cai, P. Zhou, D. Tang, P. Zhai, Q. Zhang, J Electron Mater, 44, 6, 1750-1762 (2015)

4. Y. Y. Hsiao, W. C. Chang, S. L. Chen, Energy, 35, 3, 1447-1454 (2010)

5. Y. Wang, C. Dai, S. Wang, Appl Energ, 112, 1171$1180(2013)$

6. J. LaGrandeur, Vehicle fuel economy improvement through thermoelectric waste heat recovery. DEER conference, Chicago, 2005

7. X. Liu, Y. D. Deng, Z. Li, C. Q. Su, Energ Convers Manage, 90, 121-127 (2015)

8. A. Martinez, J. G. Vian, D. Astrain, A. R. Guez, I. Berrio, J Electron Mater, 39, 9, 1463-1468 (2010)

9. K. T. Wojciechowski, J. Merkisz, P. Fuć, J. Tomankiewicz, R. Zybała, J. Leszczyński, P. Lijewski, P. Nieroda, Combustion Engines, 154 (3), 60-71 (2013)

10. X. Wang, S. Wang, L. Zhou, X. Li, Adv Mat Res, V. 986-987, p.848 (2014)

11. M. Musiał, M. Borcuch, K. Wojciechowski, J Electron Mater, 45, 3, 1517-1522 (2016)

12. X. Liu, Y.D. Deng, K. Zhang, M. Xu, Y. Xu, C.Q. Su, Appl Therm Eng, 71, 364-370 (2014)

13. J. Yu, H. Zhao, J Power Sources, 172, 428-434 (2007)

14. C. Lu, S. Wang, C.Chen, Y. Li, Appl Therm Eng, 89, 270-279 (2015)

15. L, Chen, J. Gong, F. Sun, C. Wu, Int J Therm Sci, 41, 95-99 (2002)

16. H. Lu, T. Wu, S. Bai, K. Xu, Y. Huang, W. Gao, X. Yin, L. Chen, Energy, 54, 372-377 (2013)

17. J. Esartea, G. Minb, D. M. Rowe, J Power Sources, 93, 72-76 (2001)

18. M. Hatami, D. D. Ganji, M. Gorji-Bandpy, Renew Sust Energ Rev, 37, 168-181 (2014)

19. W. He, G. Zhang, X. Zhang, J. Ji, G. Li, X. Zhao, Appl Energ, 143, 1-25 (2015) 